\title{
The Effect of Heavy Metals Cadimium, Chromium and Iron Accumulation in Human Eyes
}

\author{
Hanaa H. Haddad \\ Chemistry Department, College of Science, University of Basra, Basra, Iraq \\ Email: hanaa_hadadd@yahoo.com
}

Received May 4, 2012; revised June 13, 2012; accepted July 4, 2012

\begin{abstract}
The object of the present study is to measure the concentrations of toxic heavy metals in human eyes (cadimium and chromium) and major mineral iron ion. The heavy metals cadimium, chromium and iron were assayed using atomic absorption spectrometry. Metals determination in human eye is the most common application of biological monitoring for screening diagnosis and assessment of metals exposures and their risks. The statistical analysis of the metals (cadimium, chromium and iron) levels in human eyes showed that levels of the three metals in non-smoker were lower than metals contents of the smoker groups. Metals levels in human eyes of males were significantly lower than females. Statistically significant differences $(p<0.001)$ were observed between persons living in city centre and others who living in outskirt for concentrations of all three metals. Geographical influences are thought to be the main source of variability.
\end{abstract}

Keywords: Heavy Metals; Human Eyes; Atomic Absorption

\section{Introduction}

Human cells employ metals such as zinc, copper and iron to control significant metabolism and signling functions making them essential for life [1]. Many heavy metals play an important biological role, the particular importance of iron and copper ions in biological processes [2]. Redox-active metals such as iron, copper and chromium undergo redox recycling to produce free radicals. In contrast cadimium and mercury are redox-inactive metals that challenge antioxidant defenses by binding to thiols in cell $[3,4]$. The natural aquatic systems may extensively be contaminated with heavy metals released from domestic industrial and other man made activities [5]. The toxic effect of heavy metals usually involves an interaction between the heavy metal ion and specific target protein resulting in a change in protein structure and function [6]. Chromium in its hexavalent form which is the most toxic species of chromium is used extensively in some industries such as leather processing. The toxicity of chromium stems from its tendency to be corrosive and to cause allergic reactions. Chromium is a carcinogen, particularly of the lung through inhalation. Cell toxicity caused by heavy metal ions is attributed to oxidative and nitro sativa stress [7], defined as an oxidants over antioxidants. Macro molecules in cell are damaged by metals-induced production oxygen and nitrogen-containing free radicals (oxidants) and/or metal induced depletion of the cells antioxidant defense programmed cell death or necrotic cell death are usual consequences [8]. Oxidative stress has been recognized as underlying mechanism in toxicity associated with numerous metals. Metals either undergo redox cycling $(\mathrm{Fe}, \mathrm{Cr}$ and $\mathrm{Cu})$ or deplete cells antioxidant pool $(\mathrm{Cd}, \mathrm{Pb}$ and $\mathrm{Ni})$ and induce oxidative stress [9].

This paper deals with the quantitative determination of cadimium, chromium and iron concentration of human eyes subjects exposed to these metals along with their respective controls. The purpose of this research is to quantify the accumulation of heavy metals (cadimium, chromium and iron) in human eye lenses.

\section{Materials and Methods}

\subsection{Apparatus}

Ashimadzu atomic absorption spectrophotometer model (AA-630-12) was used with an air-acetylene burner (slot dimensions $100 \times 0.62 \mathrm{~mm}$ ). Instrument settings were: lamp current, $10 \mathrm{~mA}$; wave length, $285.2 \mathrm{~nm}$; slit width, $0.2 \mathrm{~nm}$. These conditions were maintained constant throughout the measurements.

\subsection{Reagents}

Metals stock solutions: Add $200 \mathrm{mg}$ of magnesium metals to a $100 \mathrm{ml}$ volumetric flask. Dissolve using the minimal quantity of hydrochloric acid. Dilute to volume with deionized water.

Metals working standards: Transfer $(0.5-5) \mathrm{ml}$ of the stock solution to ten a $100 \mathrm{ml}$. Volumetric flask and dilute 
to volume with deionized water. This gives a concentration of $(10$ - 100) $\mu \mathrm{g}$ Metal $/ \mathrm{ml}$.

\subsection{Preparation of Samples}

Each lens was placed into pre weight digestion tube. The sample was weighted to determine a dry weight (gram) after drying at $95^{\circ} \mathrm{C}$ overnight [7]. Next day reweighed to determine dry weight $(\mathrm{gm})$, then $(1 \mathrm{ml})$ of concentrated nitric acid was added digest tube which was placed in waterbath at $100^{\circ} \mathrm{C}$, the sample digested for approximately $1 \mathrm{~h}$. until all tissues material has been dissolved, then $(1 \mathrm{ml})$ perchloric acid was added until (deep brown color) with clear solution was obtain dilute each sample to mark with deionized water to $10 \mathrm{ml}$.

\subsection{Statistical Analysis}

The statistical analysis was carried out using two-way analysis of variance with unbalanced repeated measurements. Statistical significance between individual time points was made by using Revised Least Significant Difference (RLSD) test. The probability level for significance was $5 \%$ less.

\section{Results and Discussion}

In our laboratory the measurements of concentrations of metals, cadmium and chromium and iron in human eyes samples Table 1 show their characters. All the measurements of the eyes samples subjected to statistical analysis using the independent samples RLSD-test to compare between measurements of the study groups (smoker and none-smoker), sex (males and females) and life environment (Outskirts and citycentre).

The statistic results showed that there is a significant difference $(p<0.001)$ in the metal levels in all the compared males and females eyes measurements as shown in Figure 1 the concentration of the three metals in eyes about $10 \%$ excess in females higher than in males. From these findings, it would appear that while variation does occur in concentrations of metals in eyes with difference in sex, no definite pattern of distribution is present.

Figure 2 illustrates the variation in the concentration of metals in human eyes as a function of life environments. Statistically significant differences $(p<0.001)$ were observed between persons living in city centre and others who living in outskirt for concentrations of all three metals. Geographical influences are thought to be the main source of variability. The observed variations are probably a reflection of the varying levels present in foods that are generally dependent on geochemical environment in which they are living. Environmental contamination can also be a source of metals a human eyes.

Figure 3 illustrates that there is a statistical relationship between the metals levels in eyes of smoker and
Table 1. Study groups Charactors.

\begin{tabular}{|c|c|}
\hline Study groups & Character \\
\hline Total & 46 \\
\hline Male & 20 \\
\hline Female & 26 \\
\hline Outskitrs & 29 \\
\hline City Centre & 17 \\
\hline Smoker & 20 \\
\hline Non-Smoker & 26 \\
\hline \multicolumn{2}{|c|}{ Associated diseases } \\
\hline Hypertension & 3 \\
\hline Diabetes Millets & 2 \\
\hline \multicolumn{2}{|c|}{ Drugs } \\
\hline Mantol Fluide & 3 \\
\hline Cidamex & 4 \\
\hline Optiflox Drop & 3 \\
\hline Fucithalmic Oint. & 5 \\
\hline Betacol Drop & 1 \\
\hline Samaphinicol Oint. & 1 \\
\hline
\end{tabular}

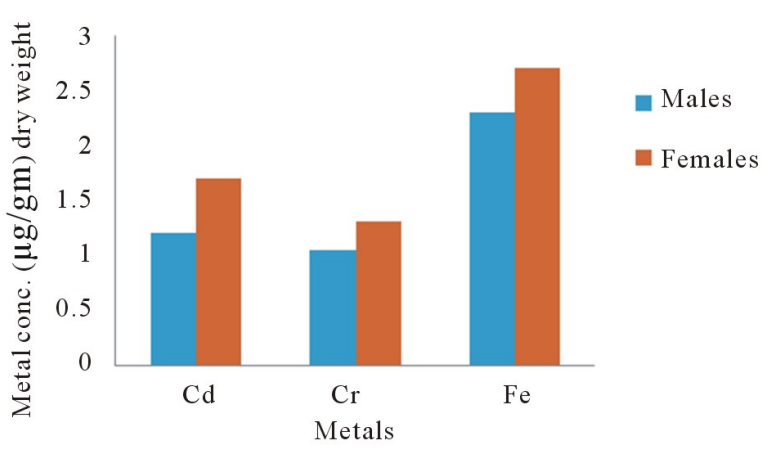

Figure 1. Concentrations of metals in human eyes as a function of sex.

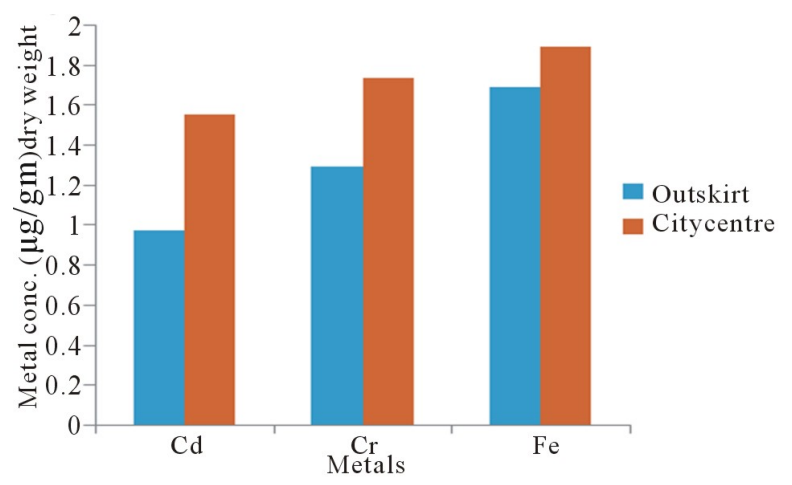

Figure 2. Metal concentrations in human eyes as a function of life environment. 


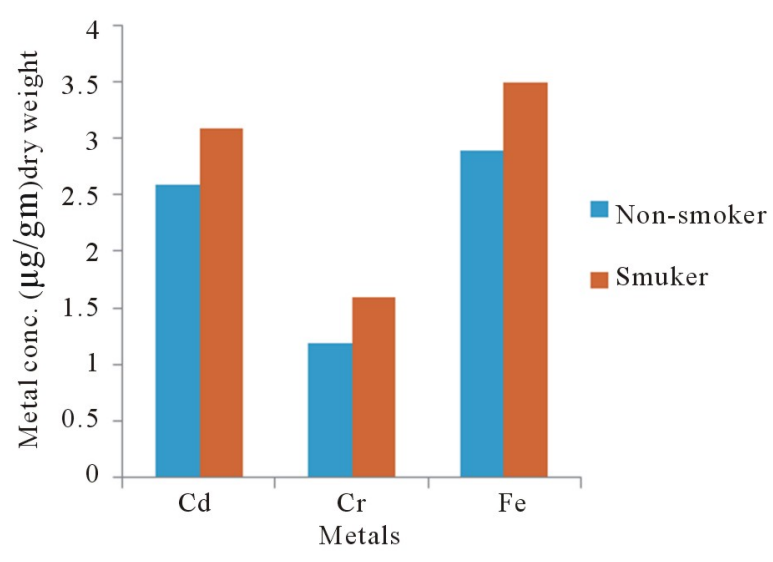

Figure 3. Metal conc. in human eyes as a function of health case.

non-smoker groups. The concentration of metals in the smokers persons was about $40 \%$ higher than in the nonsmoker persons.

This investigation demonstrates that the heavy metals such as cadmium and chromium accumulate in tissues of adult human eyes. Concentrating to the greatest extent in the retinal pigment epithelium and choroid [8] the pigmented tissues of the eye such as retinal, ciliary body of the eye have a high affinity for metal ions [10]. Melanin within the pigment granules according to atomic weight and volume such as iron [11]. Heavy metal can effectively compete for same binding sites as other metals ions and have the capacity to replace previously bound metals and after ocular metal concentration [12]. The retinal pigment epithelium is a metal chelating tissue that is capable of binding essential and toxic heavy metal due to it high affinity to melanin in retinal pigment epithelium [12]. A number of heavy metals increase in concentration in lenses of both aging people and people with cataracts, for example chromium (hexavalent) compound are toxic and known human carcinogens where as chromium (III) is an essential nutrient [13]. Iron is important for proper healing and for retarding the growth of cataracts. Parental administration of iron is an alternative to the use of oral preparation [14]. The rate response to parental therapy is similar to that which follows usual oral dose [15]. In general the increase in eye disease due to there is a decline in nutrition use of preservatives, chemicals and genetically-modified organisms (GMO) in our diet and also heavy metals position [16]. A recent article reported that cadmium and lead levels accumulate in human ocular tissue and these heavy metals may be linked on increase in degrative disorders [17]. Cataract surgery is the remived of diseased human lens which has become cloudy or opacities and is obstructing vision.

More recently metal deficiency diseases have become widely recognized and pathological conditions arising from trace elements excess have come to light, whereas chromium required is small quantities refer as trace elements. There is increasing evidence of element playing a diagnostic, curatives and preventive role in combing various diseases [18]. Whereas iron known as major mineral element. Inhaled cadmium is more efficiently absorbed and it found that each twenty cigarettes may contribute (18 - 36) mmole cadmium (2 - 4) $\mu \mathrm{g}$ [19]. The main concerns with cadmium are therefore chronic exposure in populations.

Though certain essential trace elements are required in trace amounts for various physiological processes, but at higher concentrations, these micronutrients tend to be toxic and derange various physiological processes leading there by to diseases. Therefore, it is important to determine the metal concentrations in humans to monitor and asses their impact on human health.

The high chromium concentration obtained may attributed to the chromium content in to tobacco leaves which might get incorporated in the leaves from the soil [20]. Main sources of metal in cigarettes are wrapping paper and the filter. Concentrations of chromium are influenced by smoking habits, increasing with age and smoking time but with no apparent decrease after stopping smoking [21]. The biological effect of chromium depends on its valiancy [22]. High level of iron observed is probably due to the presence of iron oxide fumes in the environment of work place as various processes involved emanate oxides of iron [23]. For non-smoker, food is the major source of cadmium exposure with typical intakes. $10-60 \mu \mathrm{g} /$ day in some regions but much higher in others due to diet and the environmental distribution of cadmium, smoking is an important source of cadmium, smokers have significantly higher concentrations of blood cadmium than non-smoker [9].

\section{Conclusion}

During my study the accumulation of trace elements between smoker and non smoker revealed significant increase of cadimium levels in smoker patients and significant decrease of chromium while there was no significant differences in iron concentration between them. The cadmium concentration in the range $1-2 \mu \mathrm{g}$ do occur in differed reference population and arise from differences in environmental exposure as well as other biological factors. So cadmium levels in human eye patients a significantly increase in comparison to healthy controls. Chromium from food and beverages is poorly absorbed and toxicity of chromium is mainly due to chromium that can be absorbed by the respiratory tract and also to certain extent by the intact skin. Smoker get exposed to significantly higher cadmium levels than non smoker severe damage to lungs may occur through breathing higher levels of cadmium. The potential ocular toxicity of these heavy metals and their possible role in eye disease re- 
quires further study.

\section{Acknowledgements}

Author wishes to thank Dr. S. Z. Alasadi and Dr. N. S. Haddad, FIBMSC CHEM. ophthalmologic department, college of medicine, university of Basra, for their available co-operating in collection of the samples.

\section{REFERENCES}

[1] S. Sataray, J. B. Baker and S. Curbenjapol, "A Global Perspective on Cadimium Pollution and Toxicity in NonOccupationally Exposed Population," Toxicology Letters, Vol. 137, No. 1-2, 2003, pp. 65-83. doi:10.1016/S0378-4274(02)00381-8

[2] B. Halliwell and T. M. Gutteridge, "Free Radicals in Biology and Medicine," Oxford University Press, Oxford, 1999.

[3] S. J. Stohs and D. Bagchi, "Oxidative Mechanism in Toxicity of Heavy Metals," Free Radical Biology and Medicine, Vol. 18, No. 2, 1995, pp. 321-336. doi:10.1016/0891-5849(94)00159-H

[4] N. Ercal, O. Gurer and B. Aykin, "Toxic Metals and Oxidative Stress, Part 1: Mechanisms Involved in Metal Induce Oxidative Damage," Current Topics Medicinal Chemistry, Vol. 1, No. 6, 2001, pp. 529-539. doi:10.2174/1568026013394831

[5] E. O. Farombi, O. A. Aclelowo and Y. R. Ajimoko, "Biomarkers of Oxidative Stress and Heavy Metal Levels as Indicators of Environmental Pollution in African Cat Fish from Nigeria Ogun River," International Journal of Environment Research and Public Health, Vol. 4, No. 2, 2007, pp. 158-165. doi:10.3390/ijerph2007040011

[6] Occupational Health and Safety Administration Safety and Health Topics, 2008. http.//www.osha.gov/SLTCmetalsheavyindex.html

[7] A. Pompello, A. Visvikis, A. Paolicchi and V. Detata, "The Changing Faces of Glutathione a Cellular Protagonist," Biochemical Pharmacology, Vol. 66, No. 8, 2003, pp. 1499-1503.

[8] M. D. Pulido and A. R. Parrish, "Metal Induced Apoptosis Mechanisms," Mutation Research, Vol. 533, No. 1-2, 2003, pp. 227-241. doi:10.1016/j.mrfmmm.2003.07.015

[9] R. Mehra and M. Juneja, "Advers Health Effects in Workers Exposed to Trace Toxic Metals at Work-Place," Indian Journal of Biochemistry \& Biophysics, Vol. 40, No. 2, 2003, pp. 131-135.

[10] E. R. Jay and M. D. John, "Heavy Metal Concentration in Human Eyes," American Journal of Ophthalmology, Vol. 139, No. 5, 2005, pp. 888-894. doi:10.1016/j.ajo.2004.12.007
[11] D. R. Baldwin and W. J. Marshall, "Heavy Metal Poisoning and Its Laboratory Investigation," Annals of Clinical Biochemistry, Vol. 36, No. 3, 1999, pp. 267-300.

[12] B. S. Larrson, "Interaction between Chemical and Melanin Pigment Cell," Research, Vol. 6, 1993, pp.127-133.

[13] A. M. Potts and P. C. Au, "The Affinity of Melanin for Inorganic Ions," Experimental Eye Research, Vol. 22, No. 5, 1976, pp. 487-491. doi:10.1016/0014-4835(76)90186-X

[14] P. Coyle, J. C. Philcox and A. M. Rofe, "Clinical Significance of Metallothionein Adealer in Heavy Metals," The Clinical Biochemical Reviews, Vol. 14, 1993, pp. 118-125.

[15] L. T. Friberg, M. Piscator and G. F. Nordberg, "Occurance, Possible Routes of Exposure and Daily Intake," In: R. West, Ed., Cadimium in Environment, CRC Press, Boca Raton, 1971 .

[16] Agency for Toxic Substances and Disease Registry, Tox FAQS, 2008. http//www.astdr.gov/Tox.fag.html

[17] M. J. Stillman and A. Presta, "Characterizing Metal Ion Interaction with Biological Molecules-The Spectroscopy of Metallothionine," Journal of Editors Molecular Biology and Toxicology of Metal, 2000, pp. 276-290.

[18] S. S. Vutukuru, "Acute Effects of Hexavalent Chromium on Survival, Oxygen Consumption, Hematological Parameters and Some Biochemical Profiles of IndIan Major Carp, Labeo Rohita," International Journal of Environmental Public Health, Vol. 2, No. 3, 2005, pp. 456-462. doi:10.3390/ijerph2005030010

[19] C. A. Bache, "Cadimium and Nickel in Main Steam Particulate of Cigarattes Containing Tobacco Grown on a Low-Cadimium Soil-Sluge Mixture," Journal of Toxcology and Environmental Health, Vol. 16, 1985, pp. 547552.

[20] A. Sukumar and R. Subramaniam, "Elements in Hair and Nails of Risidents from Avillage Adjacent to New Delhi Influence of Place of Occupation and Smoking Habits," Biological Trace Element Research, Vol. 34, No. 1, 1992, pp. 99-105. doi:10.1007/BF02783902

[21] P. Paakko, P. Kokkonen, S. Anttila and P. L. Kalliomäki, "Cadimium and Chromium as Markers of Smoking in Human Lung Tissue," Environmental Research, Vol. 49, No. 2, 1989, pp. 197-207. doi:10.1016/S0013-9351(89)80065-9

[22] W. Mertz and E. E. Reginsky, "Chromium Metabolism the Glucose Tolerance Factor, Newer Trace Element in Nutrition," Dekker, New York, 1987.

[23] M. Wolfsperger, G. Hauser, W. Göblerc and C. Schlagenhaufen, "Heavy Metals in Human Hair Sample from Austria and Italy Influence of Smoking Habit," Science of the Total Environment, Vol. 156, No. 3, 1994, pp. 235-239. doi:10.1016/0048-9697(94)90190-2 